\title{
Is the ATIC terminology oriented to nursing phenomena?
}

\author{
Maria Eulàlia Juvé-Udina \\ School of Nursing, Bellvitge Research Institute, University of Barcelona, Barcelona, Spain \\ Email: ejuve@ub.edu, ejuve@gencat.cat
}

Received 16 September 2012; revised 18 October 2012; accepted 7 November 2012

\begin{abstract}
The main goal of this observational and descriptive study is to evaluate whether the diagnosis axis of a nursing interface terminology meets the content validity criterion of being nursing-phenomena oriented. Nursing diagnosis concepts were analyzed in terms of presence in the nursing literature, type of articles published and areas of disciplinary interest. The search strategy was conducted in three databases with limits in relation to period and languages. The final analysis included 287 nursing diagnosis concepts. The results showed that most of the concepts were identified in the scientific literature, with a homogeneous distribution of types of designs. Most of these concepts $(87.7 \%)$ were studied from two or more areas of disciplinary interest. Validity studies on disciplinary controlled vocabularies may contribute to demonstrate the nursing influence on patients' outcomes.
\end{abstract}

Keywords: Interface Terminology; Nursing Diagnosis; Controlled Vocabularies; Nursing Classifications; Electronic Health Records; Content Validity

\section{INTRODUCTION}

In the context of the health information systems, two main categories of languages are described: Standardized vocabularies, like classifications and taxonomies and uncontrolled vocabularies, essentially the natural language $[1,2]$.

Nursing controlled vocabularies generation started in the early 70s in order to describe nursing phenomena and since then, it has been associated to the theoretical development aiming to identify, define, and classify disciplinary concepts in order to improve nursing education, management and clinical practice [2].

Increasing pressure on healthcare systems to gain efficiency, quality and productivity is challenging nurses to demonstrate the impact of their professional services on health outcomes in individuals and communities, so standardized computer-compatible professional terminol- ogies are becoming a requirement. In this sense, language systems development and evaluation have been included as priorities into the nursing international agendas [3-5].

Worldwide efforts in nursing terminological works are reflected in the American Nurses Association (ANA) recognition program for terminologies as supporting nursing practice, including several controlled vocabularies like the North American Nursing Diagnosis Association Taxonomy (NANDA-I), the Nursing Interventions Classification (NIC), the Clinical Care Classification (CCC), the Nursing Outcomes Classification (NOC) or the Omaha System among others [6]. In this same way, the International Council of Nurses (ICN) has been increasingly investing efforts in the development of a unified nursing language system, that is, the International Classification for Nursing Practice (ICNP) [7].

Institutions and researchers from different countries have joined this professional mandate designing, implementing and evaluating controlled vocabularies for nursing practice [4,8-12].

Despite the achievements, one of the reasons for the use of these terminologies in computer-based systems is not universal is that "in the clinical practice, nurses use terms other than those in standardized vocabularies" [3]. It has been suggested in the recent literature, that nurses refer standardized nursing languages reduce the "individualized approach" of nursing care and documentation, because these vocabularies are not able to reflect subtle changes in patient status and "they may foster inaccuracies in patients' information in reporting clinical events" [13]. Similarly, the results of a survey conducted in the United States showed that most nurses had no experience with or knowledge of any nursing controlled vocabulary, being the NANDA framework "the most recognizable with over $1 / 3$ of respondents reporting that they had used it in nursing school, but not since" [14].

This article focuses on a nursing interface terminology, termed ATIC. Interface terminologies are controlled vocabularies, based on close to natural language concepts, optimized for end-user data entry, aimed to ease a friendly use of the terminological system within the electronic health records (EHR) [15,16]. 
The ATIC terminology has been used for representing nursing phenomena in the electronic health records system implemented in 11 hospitals in Catalonia. This vocabulary is structured in three main axes: Assessment, diagnosis/outcomes and interventions. Details contained in the description of each concept are listed in Table $\mathbf{1 .}$

Further information on the evolving status of the coverage and the general structure of this interface vocabulary, as well as its philosophical, theoretical and methodological background and other related studies are published elsewhere [17-23].

As any other clinical instrument, the use of a particular nursing terminology should be evaluated. Validity evaluation criteria for nursing controlled vocabularies described in the literature include, among others, that the terminology should be research-based and nursing phenomena-oriented [4].

The main goal of this study was to evaluate to what extent the diagnosis axis of the ATIC terminology is oriented to nursing phenomena, as a measure of its content validity.

\section{METHOD}

\subsection{Design}

This study applied an observational, descriptive design, using the technique of contrast with previous data, that is, a literature review strategy to identify the disciplinary scientific production on the diagnostic concepts included in the ATIC terminology.

\subsection{Sample}

The objects of the study were the concepts within the diagnosis axis of the ATIC terminology. Concepts under development or refinement at the time of starting the study were excluded. Sample size was calculated considering an $80 \%$ estimated proportion (P), with a $95 \%$ confidence level $(\alpha=0.05)$ and a 0.05 precision (i). Sample size resulted in 246 objects of study. A correction formula was applied to the sample size $(\mathrm{Na}=\mathrm{N}[1 /(1-\mathrm{R})])$ to keep statistical power in case of potential losses due to missed data or other reasons. Corrected sample size was estimated at 287 concepts to be included in the final analysis.

Concepts were randomly selected applying a random number list to the terms in the diagnosis axis of the terminology. Random numbers were obtained using the random generation function of Excel (Microsoft, Redmond, WA).

\subsection{Data Collection}

Nursing research papers related to the concepts randomly included in the study were searched in the following healthcare databases: Pubmed

(http://www.ncbi.nlm.nih.gov/pubmed/), the Cochrane Library (http://www.cochrane.es/) and the Scientific Electronic Library Online (http://www.scielo.cl/).

Search limits were established in relation to language and time. Publication languages included were English, French, Portuguese, Catalan, Spanish and Italian. The review was performed considering a maximum of 20 years back in time. Redundancy was considered as an end point of the reviewing process before reaching the whole 20-year back period.

Quantitative and qualitative research designs were considered. Editorials, letters, news and historical articles were excluded. Located references in the databases with no abstract available were also excluded.

Research designs were classified into three main categories:

The first group included case studies, case series, reviews as well as concept analysis or concept development designs;

The second category included quantitative descriptive designs, validation studies and qualitative ethnographies, exploratory, grounded-theory and phenomenological studies;

The third category of studies included analytical designs, controlled trials, meta-analysis and qualitative metasynthesis.

Criteria were settled to systematically address the search for each concept: Keywords for the concept under study and its synonyms plus the word "nursing” (and/or midwifery if applicable) were used both for actual and risk diagnosis concepts. For risk diagnosis concepts, the search also included the keywords "prevention" (first search) and "risk factors" (second search) (Figure 1).

A short standardized data collection sheet was designed to document the research variables for each concept including:

1) Presence of the concept in the nursing literature,

2) Types of articles and,

3) Areas of disciplinary interest.

The first topic, the presence of the concepts in the disciplinary literature was defined as a dichotomyc variable: Presence of the concept, Yes or Not.

Types of designs were organized in three categories as previously described.

Areas of disciplinary interest were classified into five main domains: 1) Medical-Surgical Nursing, also including critical care and emergency nursing; 2) MaternalChild and Pediatric Nursing; 3) Family and Community Nursing; 4) Mental Health Nursing; and 5) other areas of disciplinary interest (including research papers on nursing ethics, politics, management, economics, education and theory development).

Geriatric nursing was considered in the Medical-Sur- 
Table 1. Basic elements included in each concept construction (IA) = if applicable.

\begin{tabular}{|c|c|}
\hline Elements & Meaning \\
\hline Code & Alphanumerical, non-contextual, random coding system. \\
\hline Term & Concept label. \\
\hline Concept meaning & Operational definition. \\
\hline Additional information & $\begin{array}{l}\text { Comments to further explain the concept origins. For diagnostic concepts, this section also includes information on } \\
\text { risk and related factors, signs and symptoms and cues to differential diagnosis. }\end{array}$ \\
\hline Concept roots & Hierarchical relation of the concept with components and dimensions. \\
\hline Conceptual development & Madurational level of the concept. \\
\hline Terminological features & Concept compositionality, granularity, and mapping. \\
\hline Concept translation & From Catalan into English, Spanish, French, Italian, Portuguese and Russian. \\
\hline Evidence & References supporting the concept. \\
\hline
\end{tabular}

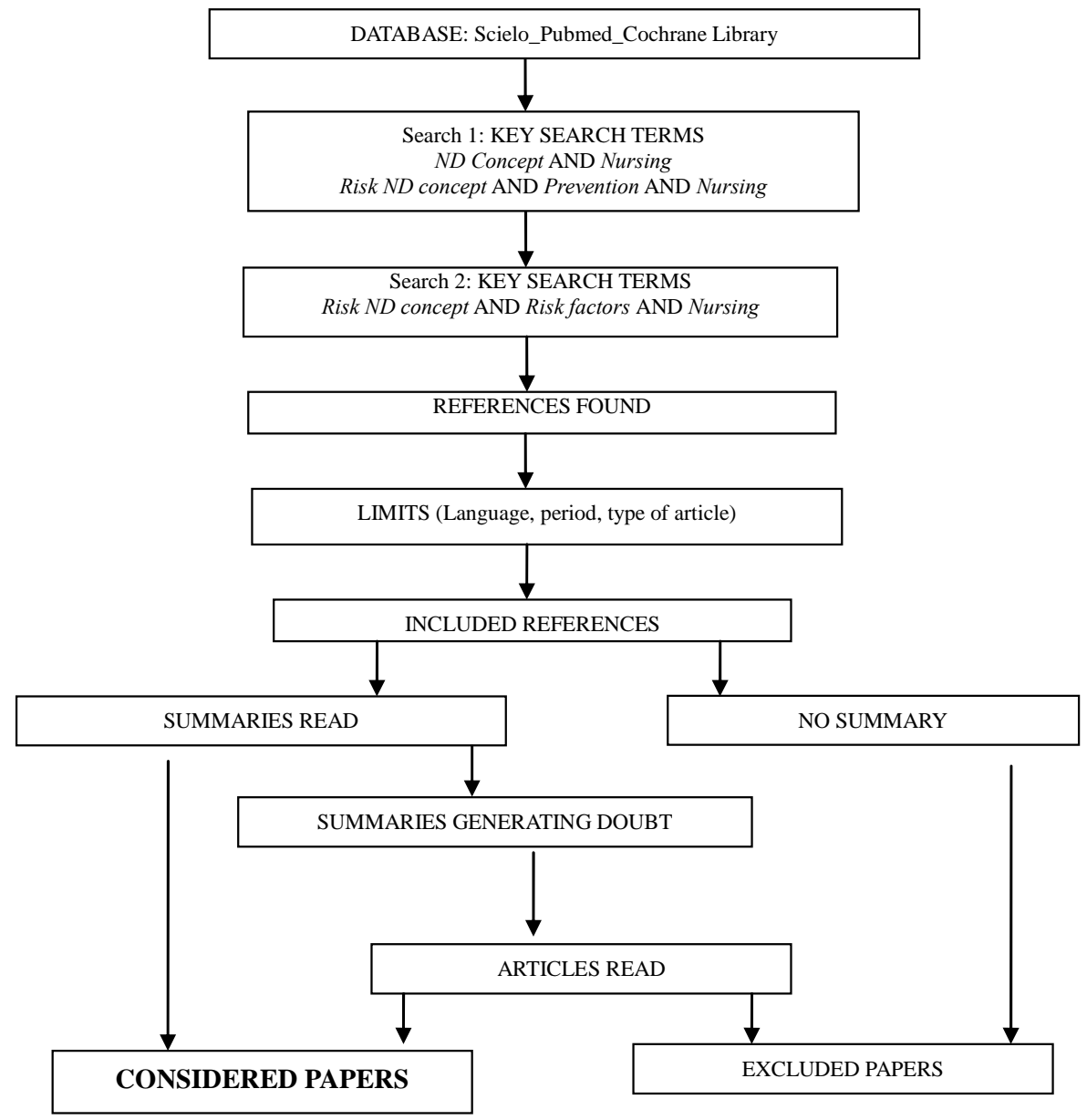

Figure 1. Literature search process.

gical Nursing domain for elder hospital in-patients and in the Family and Community Nursing domain for elder outpatients, elder people living in the community and nursing home residents.

Home healthcare nursing was also considered in the
Family and Community Nursing domain, except for hightech home healthcare nursing, which was included in the Medical-Surgical Nursing domain.

Data were systematically collected from July 2nd 2010 to January 31st 2012. 


\subsection{Data Analysis}

Main outcome measures were the global score for the presence of the diagnostic concepts in the nursing literature and the distribution scores for the other two topics: Types of studies and areas of disciplinary interest.

Data were processed onto an Excel spreadsheet (Microsoft, Redmond, WA) and revised to identify potential processing errors or inconsistencies. Descriptive analysis of the main outcomes including frequencies in percentages, means and standard deviations when applicable were used. Confidence interval was calculated for a confidence level of $95 \%$.

\section{RESULTS}

The final analysis included 287 concepts from the diagnosis axis of ATIC, 203 corresponding to actual nursing diagnosis concepts and 84 to risk nursing diagnosis (29.2\%). The search process allowed the researcher to consider 7731 paper summaries. Mean number of references selected per concept was 25.5 (CI 2.09).

According to this analysis, the main results for the outcome measures indicate that $98.7 \%$ of the concepts included in the study were identified as "being present" in the nursing research literature. Four nursing diagnoses included in this analysis, did not match any nursing scientific production: Newborn physiological immaturity, abulia, situational emotional claudication, and risk for unintended self-exclusion.

Distribution results for the types of designs ranked analytical and meta-analytical studies at the top representing a $44.1 \%$; followed by category 2 designs (quailtative and quantitative descriptive studies) obtaining a $35.6 \%$ and $19.7 \%$ for category 1 designs (case studies, case series and reviews). Sample diagnosis labels within each of these categories are listed in Table 2.

Rank distribution of concepts matching nursing research studies, organized by areas of disciplinary interest placed first Medical-Surgical Nursing ( $\mathrm{N}=248$ concepts; 86.4\%), followed by Maternal-Child and Pediatric Nursing ( $\mathrm{N}=232$ concepts; 80.8\%), Family and Community Nursing ( $\mathrm{N}=170$ concepts; 59\%), other areas of disciplinary interest ( $\mathrm{N}=131$ concepts; $45.6 \%$ ) and finally Mental Health Nursing ( $\mathrm{N}=108$ concepts; 37.6\%).

Nursing diagnosis concepts falling into two or more of these areas accounted for $87.7 \%$. Figure 2 describes the basic distribution for nursing diagnosis concepts falling into one or more areas of disciplinary interest.

Table 3 shows a matrix with sample nursing diagnoses of the ATIC terminology falling into the different areas of disciplinary interest.

\section{DISCUSSION}

The results seem to support that the ATIC terminology

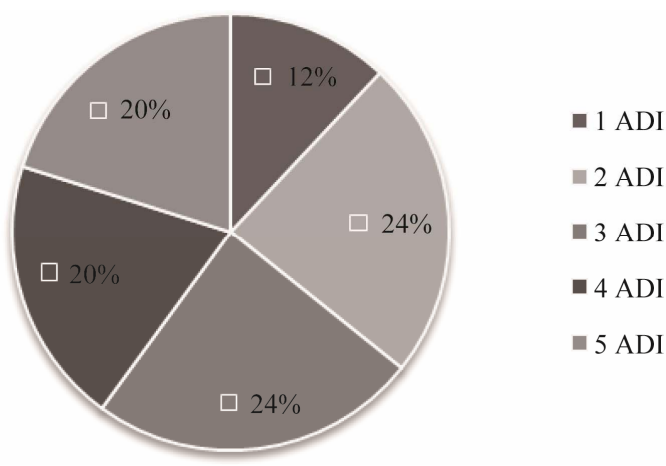

Figure 2. Distribution (\%) of concepts within areas of disciplinary interest (ADI).

Table 2. Sample diagnosis labels within each design category.

\begin{tabular}{lll}
\hline Designs & $\begin{array}{l}\text { Sample actual } \\
\text { nursing diagnoses }\end{array}$ & $\begin{array}{l}\text { Sample risk nursing } \\
\text { diagnoses }\end{array}$ \\
\hline Type 1 & $\begin{array}{l}\text { Unilateral neglect } \\
\text { Extravasation } \\
\text { Parental chronic low } \\
\text { self-esteem }\end{array}$ & $\begin{array}{l}\text { Risk for increased intraocular } \\
\text { pressure } \\
\text { Risk for hyperthermia } \\
\text { Risk for autonomous dysreflexia }\end{array}$ \\
& $\begin{array}{l}\text { External infestation } \\
\text { Spiritual distress }\end{array}$ & $\begin{array}{l}\text { Risk for hyper/hypoglycemia } \\
\text { Risk for extravasation }\end{array}$ \\
& $\begin{array}{l}\text { Separation anxiety } \\
\text { Impaired family dynamics }\end{array}$ & $\begin{array}{l}\text { Risk for anaphylaxis } \\
\text { Risk for compartment syndrome }\end{array}$ \\
& Acute pain & Risk for increased intracranial \\
Chronic pain & pressure \\
Rypeast engorgement & Risk for corneal abrasion \\
Risk for delayed gastric emptying \\
\end{tabular}

meets the content validity criterion of orientation to nursing phenomena. Most of its concepts are included in the nursing research literature, these concepts have been studied using different types of designs and from diverse nursing specialties.

The results presented herein are consistent with the findings of a previous study on the evaluation of the face validity of the ATIC terminology [23].

To the author's knowledge, no similar studies have been published based on other nursing diagnosis controlled vocabularies. Searching in Pubmed for "Nursing Diagnosis" and "Content validity", from 2012 back to 1991 and language limited to English, Portuguese, Catalan, Spanish, French and Italian, retrieved 40 results. Only three of these research papers were related to whole controlled-vocabulary content validity, but two of them did not present any method nor result on that, just a consideration of its importance for building such terminological systems [11,12]. The other study, considered cultural adaptation of the OMAHA system and measured content validity using the inter-rater reliability with a panel of six nursing students [24].

Another located study on content validity and nursing diagnosis focused on the assessment of the psychometric 
Table 3. Sample diagnostic labels matching different areas of disciplinary interest (MSN: Medical surgical nursing; MCPN: Maternal-Child and pediatric nursing; FCN: Family and community nursing; MHN: Mental health nursing; OADI: Other areas of disciplinary interest).

\begin{tabular}{|c|c|c|c|c|c|}
\hline Concept label/Area of disciplinary interest & MSN & MCPN & FCN & MHN & OADI \\
\hline Parental defensive coping & & $\mathrm{X}$ & & & \\
\hline Risk for acute pulmonary edema & $\mathrm{X}$ & & & & \\
\hline Risk for caregiver situational low self-esteem & $\mathrm{X}$ & & & & \\
\hline Risk for complicated uterine dynamics & & $\mathrm{X}$ & & & \\
\hline Risk for delayed gastric emptying & $\mathrm{X}$ & & & & \\
\hline Risk for hypopotassemia & $\mathrm{X}$ & & & & \\
\hline Risk for joint contractures & $\mathrm{X}$ & & & & \\
\hline Risk for parental situational low self-esteem & & $\mathrm{X}$ & & & \\
\hline Skin cracks & & $\mathrm{X}$ & & & \\
\hline Unilateral neglect & $\mathrm{X}$ & & & & \\
\hline Autonomous dysreflexia & $\mathrm{X}$ & $\mathrm{X}$ & & & \\
\hline Ineffective breastfeeding & & $\mathrm{X}$ & & & $\mathrm{X}$ \\
\hline Infant colic & & $\mathrm{X}$ & $\mathrm{X}$ & & \\
\hline Moist desquamation & $\mathrm{X}$ & $\mathrm{X}$ & & & \\
\hline Newborn jaundice & & $\mathrm{X}$ & $\mathrm{X}$ & & \\
\hline Parental chronic sorrow & & $\mathrm{X}$ & & $\mathrm{X}$ & \\
\hline Parental fatigue & & $\mathrm{X}$ & & $\mathrm{X}$ & \\
\hline Parental powerlessness & & $\mathrm{X}$ & & $\mathrm{X}$ & \\
\hline Risk for complicated grieving & & $\mathrm{X}$ & & $\mathrm{X}$ & \\
\hline Risk for hypercalcemia & $\mathrm{X}$ & $\mathrm{X}$ & & & \\
\hline Extravasation & $\mathrm{X}$ & $\mathrm{X}$ & & & $\mathrm{X}$ \\
\hline Fecal impaction & $\mathrm{X}$ & $\mathrm{X}$ & $\mathrm{X}$ & & \\
\hline Impaired family dynamics & $\mathrm{X}$ & $\mathrm{X}$ & & $\mathrm{X}$ & \\
\hline Parental hopelessness & & $\mathrm{X}$ & $\mathrm{X}$ & $\mathrm{X}$ & \\
\hline Physiological anxiety & $\mathrm{X}$ & $\mathrm{X}$ & $\mathrm{X}$ & & \\
\hline Risk for corneal abrasion & $\mathrm{X}$ & $\mathrm{X}$ & & & $\mathrm{X}$ \\
\hline Risk for hyper/hypoglycemia & $\mathrm{X}$ & $\mathrm{X}$ & $\mathrm{X}$ & & \\
\hline Risk for increased intracranial pressure & $\mathrm{X}$ & $\mathrm{X}$ & & & $\mathrm{X}$ \\
\hline Risk for pulmonary aspiration & $\mathrm{X}$ & $\mathrm{X}$ & $\mathrm{X}$ & & \\
\hline Self-care deficit: Hygiene & $\mathrm{X}$ & & $\mathrm{X}$ & & $\mathrm{X}$ \\
\hline Complicated grieving & $\mathrm{X}$ & $\mathrm{X}$ & $\mathrm{X}$ & $\mathrm{X}$ & \\
\hline Defensive coping & $\mathrm{X}$ & $\mathrm{X}$ & & $\mathrm{X}$ & $\mathrm{X}$ \\
\hline Dehydration & $\mathrm{X}$ & $\mathrm{X}$ & $\mathrm{X}$ & & $\mathrm{X}$ \\
\hline Diaper rash & $\mathrm{X}$ & $\mathrm{X}$ & $\mathrm{X}$ & & $\mathrm{X}$ \\
\hline Dysphagia & $\mathrm{X}$ & $\mathrm{X}$ & $\mathrm{X}$ & & $\mathrm{X}$ \\
\hline Hypothermia & $\mathrm{X}$ & $\mathrm{X}$ & $\mathrm{X}$ & & $\mathrm{X}$ \\
\hline Physical frailty & $\mathrm{X}$ & $\mathrm{X}$ & $\mathrm{X}$ & & $\mathrm{X}$ \\
\hline Risk for arrhythmia & $\mathrm{X}$ & $\mathrm{X}$ & & $\mathrm{X}$ & $\mathrm{X}$ \\
\hline Risk for hemorrhage & $\mathrm{X}$ & $\mathrm{X}$ & $\mathrm{X}$ & & $\mathrm{X}$ \\
\hline Self-care deficit: Feeding & $\mathrm{X}$ & & $\mathrm{X}$ & $\mathrm{X}$ & $\mathrm{X}$ \\
\hline Acute pain & $\mathrm{X}$ & $\mathrm{X}$ & $\mathrm{X}$ & $\mathrm{X}$ & $\mathrm{X}$ \\
\hline Aggressiveness & $\mathrm{X}$ & $\mathrm{X}$ & $\mathrm{X}$ & $\mathrm{X}$ & $\mathrm{X}$ \\
\hline Chronic pain & $\mathrm{X}$ & $\mathrm{X}$ & $\mathrm{X}$ & $\mathrm{X}$ & $\mathrm{X}$ \\
\hline Diarrhea & $\mathrm{X}$ & $\mathrm{X}$ & $\mathrm{X}$ & $\mathrm{X}$ & $\mathrm{X}$ \\
\hline Fatigue & $\mathrm{X}$ & $\mathrm{X}$ & $\mathrm{X}$ & $\mathrm{X}$ & $\mathrm{X}$ \\
\hline Fecal incontinence & $\mathrm{X}$ & $\mathrm{X}$ & $\mathrm{X}$ & $\mathrm{X}$ & $\mathrm{X}$ \\
\hline Powerlessness & $\mathrm{X}$ & $\mathrm{X}$ & $\mathrm{X}$ & $\mathrm{X}$ & $\mathrm{X}$ \\
\hline Risk for falling & $\mathrm{X}$ & $\mathrm{X}$ & $\mathrm{X}$ & $\mathrm{X}$ & $\mathrm{X}$ \\
\hline Risk for nutritional deficit & $\mathrm{X}$ & $\mathrm{X}$ & $\mathrm{X}$ & $\mathrm{X}$ & $\mathrm{X}$ \\
\hline Risk for suicide & $\mathrm{X}$ & $\mathrm{X}$ & $\mathrm{X}$ & $\mathrm{X}$ & $\mathrm{X}$ \\
\hline
\end{tabular}


properties of a tool to evaluate the quality of nursing diagnoses in the care plans documented by nurses, but it did not evaluate the validity of the vocabulary [25].

The literature search on this topic also offered studies on single nursing diagnosis content validity, which were mainly observational designs. Some measured the level of agreement and disagreement among experts on the operational definition of a specific nursing diagnosis concept and others used the Ferhing's model and presented descriptive statistics on a single population of patients. This model was designed to guide nurses in the validation process of each single nursing diagnosis, not to evaluate the content validity of a whole terminology. According to Ferhing, a nursing diagnosis is valid if it is properly evidence-based [26-30].

A second search was conducted in Pubmed to locate research papers on "controlled vocabularies" and "content validity” from 2012 back to 2000. This search displayed 22 results, mainly focused on the World Health Organization International Classification of Functioning Disability and Health [31-33].

Given the difficulties found in locating similar studies, in the absence of a tool to measure the content validity criterion of orientation to nursing phenomena and taking into account the recommendation to develop nursing diagnosis content validity studies to match quantitative, descriptive designs [34], it was decided to assess whether the diagnosis axis of the ATIC terminology was nursing phenomena-oriented using such a design presented, but overall this study has some limitations that must be mentioned.

First, the classical method of content validity evaluation includes expert raters or judging panels and the calculation of the content validity ratio. In this study, an alternative method was used considering the technique of contrast with previous data described in the methodology literature [35].

Second, language limits were introduced to warrant the author could read not only the abstracts located but when needed, the whole articles. The exclusion of languages such as German, Chinese or Korean has probably influenced the results because the nursing research production in German speaking countries and in Asian nursing journals is increasingly growing.

Third, no pilot testing of the collection data tool was performed, so this should also be considered a limitation.

Forth, the domains described to organize the areas of disciplinary interest in this study were based on a previous analysis of the nursing scientific production [36]. Differences in nursing educational levels and nursing specialties among countries, made it difficult to categorize these areas synthetically. In any case, these domains seem to be quite universally recognized, as reflected in the articles found, although they were presented only for the purposes of this study and they are not intended to have any other use.

Fifth, a significant limitation of this analysis is the fact that the Cumulative Index of Nursing and Allied Health Literature (CINAHL) and the Joanna Briggs Institute for evidence-based nursing were not included as a search databases. In this study three databases and a multilanguage search strategy were used; this could be considered as a compensatory factor.

Finally, an effect has been observed in relation to the granularity of the concepts. Granularity refers to "the level of detail that a term in a standardized terminology represents" [37]. Controlled terminologies may include concepts with different levels of granularity, form general topic concepts to very specific ones. "The need for granularity varies with the need of the users. For patient care it needs to be at the lowest level, for research often less granularity will suffice” [37].

In this case, the granularity effect may have influenced the findings because the search for general concepts like anxiety may implicitly displayed results from other more specific diagnoses, like separation anxiety. In this study, when the granularity effect was detected in the summaries or the articles read, the located references where redirected to the more specific concept and were not considered for the general one. This fact could have unwillingly introduced potential bias in the results.

Although the NANDA_I Taxonomy contains different conceptual granularity levels, surprisingly, none of the content validity studies on single nursing diagnosis identified in the literature discuss this granularity effect.

Like in other nursing terminological systems, in the ATIC terminology various levels of concept granularity exist because they are intended to cover multiple clinical situations and diverse nursing levels of professional proficiency, form novice to expert nurses. It was not the aim of this study to determine the effects of concept granularity on outcomes, nor to explore the relationship between nurses' expertise and clinical judgments expressed through the use of different nursing diagnosis labels, but further research is probably needed in this sense in any nursing diagnosis terminological system.

From this analysis, several implications arise for nursing practice, research, management and education.

The first is that in this study, four nursing diagnosis concepts did not match any nursing scientific production. It could be hypothesized that some phenomena nurses diagnose in the clinical settings are not well studied, properly defined or still not submitted to theoretical concept development. This may be related to an existing gap between theory and practice and also, with the pragmatic use of language nurses have to meet the need of a term to identify and document a judgment; although this statement cannot be proven with such a design presented. 
Transcultural validation studies may be needed to reach a better understanding of the differences that may exist on the meanings and the terms, among nursing communities around the globe.

Further research should also be conducted to clarify why some diagnoses, which are contained within the ATIC terminology but also within other nursing language systems such as the NANDA_I Taxonomy, the CCC or the ICNP, are so poorly studied. This is the case, for example, for the diagnosis "Unilateral neglect" which has a very scarce scientific production matching only Type 1 designs.

It should also be taken into account that types of research designs identified for each concept may be indirect indicators of the nurses' autonomy to manage or prevent a health problem. This hypothesis may lead to increase the interest on exploring the relationship between nursing diagnosis concepts and nursing professional accountability, as well as to further clarify evidence-based issues related to the nursing language systems content. In this same sense, professional nurses and nursing students should be educated on analyzing and critically appraising disciplinary vocabularies. Nursing interface terminologies are not intended to substitute classifications but to complement them and most important, to facilitate the interactions between the nursing language systems and the electronic health records users. Nurses in daily clinical practice may benefit from a valid, reliable and easy to use entry controlled vocabulary to help them demonstrate the influence of their professional services on the health outcomes of patients and communities. Nursing and other healthcare managers should not underestimate the importance of using controlled vocabularies for healthcare information systems that have been submitted to formal evaluation studies. The selection process of a controlled vocabulary for data entry in the electronic health records at the point of care should include these considerations.

To conclude, the results of this study contribute to demonstrate that the diagnosis axis of the ATIC Terminology meets the content validity criterion of being oriented to nursing phenomena.

\section{ACKNOWLEDGEMENTS}

I would like to thank Drs. Maria Teresa Icart and Jordi Carratalà for the final review of the manuscript.

\section{REFERENCES}

[1] Thoroddsen, A. and Thorsteinsson, H.S. (2001) Nursing diagnosis taxonomy across the Atlantic Ocean: Congruence between nurse's charting and the NANDA taxonomy. Journal of Advanced Nursing, 37, 372-381. doi:10.1046/j.1365-2648.2002.02101.x
[2] Ozbolt, J. (2000) Terminology standards for nursing. Journal of the American Medical Informatics Association, 7, 517-522. doi:10.1136/jamia.2000.0070517

[3] Bakken, S., Cashen, M.S., Mendoca, E.A., O’Brien, A. and Zieniewicz, J. (2000) Representing nursing activities within a concept-oriented terminological system: Evaluation of a type definition. Journal of the American Medical Informatics Association, 7, 81-90. doi:10.1136/jamia.2000.0070081

[4] Müller-Staub, M., Lavin, M.A., Needham, I. and van Achterberg, T. (2007) Meeting the criteria of a nursing diagnosis classification. Evaluation of the ICNP, ICF, NANDA and ZEFP. International Journal of Nursing Studies, 44, 702-713.

[5] Bakken. S., Stone, P.W. and Larson, E.L. (2008) A nursing informatics research agenda for 2008-18: Contextual influences and key components. Nursing Outlook, 56, 206-214. doi:10.1016/j.outlook.2012.06.001

[6] Ozbolt, J. (2003) ANA recognized terminologies that support nursing practice. http://printfu.org/ozbolt

[7] Coenen, A. and Bartz, C. (2006) A unified nursing language system. Nursing Outlook, 54, 362-364. doi:10.1016/j.outlook.2006.09.009

[8] Hannah, K.J., White, P.A., Nagle, L.M. and Pringle, D.M. (2009) Standardizing nursing information in Canada for inclusion in the electronic health records: C-HOBIC. Journal of the American Medical Informatics Association, 16, 524-530.

[9] Ehrenberg, A., Ehnfords, M. and Thorell-Ekstrand, I. (1996) Nursing documentation in patients records: Experience of the use of the VIPS model. Journal of Advanced Nursing, 24, 853-867. doi:10.1046/j.1365-2648.1996.26325.x

[10] Wieteck, P. (2008) Furthering the development of standardized nursing terminology through an ERP-ICNP crossmapping. International Nursing Review, 55, 296-304.

[11] Mac Neela, P., Scott, P.A., Treacy, M.P. and Hyde, A. (2006) Nursing minimum data sets: A conceptual analysis and review. Nursing Inquiry, 13, 44-51. doi:10.1111/j.1440-1800.2006.00300.x

[12] Kleinbeck, S.V. (1999) Development of the perioperative nursing data set. American Operating Room Nurses Journal, 70, 15-18, 21-23, 26-28.

[13] Carrington, J.M. (2012) The usefulness of nursing languages to communicate a clinical event. CIN Computers Informatics Nursing, 30, 82-88. doi:10.1097/NCN.0b013e318224b338

[14] Schwiran, P.M. and Thede, L.Q. (2011) Informatics: The standardized nursing terminologies: A national survey of nurses' experiences and attitudes-Survey I. The Online Journal of Issues in Nursing, 16.

http://www.nursingworld.org/MainMenuCategories/ANA Markeplace/ANAPeriodicals/OJIN/TableofContents/Vol16-2011/No2-May-2011/Standardized-Nursing-Terminol ogies.html

[15] Trent Rosenbloom, S., Miller, R.A., Johnson, K.B., Elkin, P.L. and Brown, S.H. (2006) Interface terminologies: Facilitating direct entry of clinical data into the electronic health record systems. Journal of the American Medical 
Informatics Association, 13, 277-288. doi:10.1197/jamia.M1957

[16] Trent Rosenbloom, S., Miller R.A., Johnson K.B., Elkin P.L. and Brown S.H. (2008) A model for evaluating interface terminologies. Journal of the American Medical Informatics Association, 15, 65-76. doi:10.1197/jamia.M2506

[17] Juvé-Udina, M.E. (2005) Development of a clinical assessment system based on the theory of complexity and the nursing science. Nursing (Spanish Edition), 23, 50-55.

[18] Juvé-Udina, M.E. (2012) Philosophical and theoretical foundations for the development and validation of a nursing interface terminology. Part I. Revista de Enfermería, 35, 2025.

[19] Juvé-Udina, M.E. (2012). ATIC. A nursing interface terminology. Part II. Revista de Enfermería, 35, 48-55.

[20] Juvé-Udina, M.E. (2012) Health, environment and nursing. Philosophical and theoretical foundations for the development and validation of a nursing interface terminology. Part III. Revista de Enfermería, 35, 9-14.

[21] Juvé-Udina, M.E. (2012) Nursing interface terminology: Conceptual framework and interpretative analysis of the nursing process. Nursing (Spanish Edition), 30, 62-66.

[22] Juvé-Udina, M.E., Gonzalez-Samartino, M. and Matud-Calvo, C. (2012) Mapping the diagnosis axis of a new interface terminology to the NANDA international taxonomy. International Scholarly Research Network Nursing, 2012. doi:10.5402/2012/676905

[23] Juvé-Udina, M.E. (2012) A nursing interface terminology: Evaluation of face validity. Open Journal of Nursing, 2, 196-203. doi:10.4236/ojn.2012.23030

[24] Erdogan, S. and Esin, N.M. (2006) The Turkish version of the Omaha system: Its use in practice-based family nursing education. Nurse Education Today, 26, 396-402. doi:10.1016/j.nedt.2005.11.009

[25] Müller-Staub, M., Lunney, M., Odenbreit, M., Needham, I., Lavin, M.A. and van Achterberg, T. (2009) Development of an instrument to measure the quality of documented nursing diagnoses, interventions and outcomes: The Q-DIO. Journal of Clinical Nursing, 18, 1027-1037. doi:10.1111/j.1365-2702.2008.02603.X

[26] Pereira de Melo, R., Venícios de Oliveira Lopes, M., Leite de Araujo, T., de Fatima da Silva, L., Aline Arrais Sampaio Santos, F. and Moorhead, S. (2011) Risk for decreased cardiac output: Validation of a proposal for nursing diagnosis. Nursing Critical Care, 16, 287-294. doi:10.1111/j.1478-5153.2011.00453.x
[27] Gurková, E., Ziaková, K. and Cáp, J. (2011) Content validation of hopelessness in Slovakia and Czech Republic. International Journal of Nursing Terminologies and Classifications, 22, 33-39. doi:10.1111/j.1744-618X.2010.01173.X

[28] Melo, A.S., Campos de Carvalho, E. and Haas, V.J. (2008) Defining characteristics, validated by specialists and manifested by patients: A study of the sexual dysfunction and ineffective sexuality pattern diagnoses. Revista LatinoAmericana de Enfermagem, 16, 951-958. doi:10.1590/S0104-11692008000600003

[29] Guirao-Goris, J.A. and Duarte-Climents, G. (2007) The expert nurse profile and diagnostic content validity of sedentary lifestyle: The Spanish validation. International Journal of Nursing Terminologies and Classifications, 18, 84-92. doi:10.1111/j.1744-618X.2007.00056.X

[30] Ferhing, R.J. (1987) Methods to validate nursing diagnosis. Heart \& Lung, 16, 625-629.

[31] Cieza, A. and Stucki, G. (2008) The international classification of functioning disability and health: Its development process and content validity. European Journal of Physical Rehabilitation Medicine, 44, 303-313.

[32] Fairbairn, K., May, K., Yang, Y., Balasundar, S., Hefford, C. and Abbott, J.H. (2012) Mapping patient-specific functional scale (PSFS) items to the international classification of functioning, disability and health (ICF). Physical Therapy, 92, 310-317. doi:10.2522/ptj.20090382

[33] Glässel, A., Kirchberger, I., Kollerits, B., Amann, E. and Cieza, A. (2011) Content validity of the extended ICF core set for stroke: An international Delphi survey of physical therapists. Physical Therapy, 91, 1211-1222. doi:10.2522/ptj.20100262

[34] Carrillo-Gonzalez, G.M. and Rubiano Mesa, Y.L. (2007) Validation research in nursing diagnosis. Revista Cubana de Enfermería, 23, 1-11.

[35] Argimon, J.M. and Jiménez, J. (2005) Clinical and epidemiological research methods. 3rd Edition, Elsevier, Barcelona.

[36] Juvé-Udina, M.E., Pastor-Maylin, L., Estrem-Cuesta, M. M., Blanco-Aguilar, C., Verge-Monedero, J.M., CoidurasCharles, A., et al. (2011) What do nurses look after? Crosssectional study on recent nursing scientific production. Nursing (Spanish Edition), 29, 56-59.

[37] Sewell, J.P. and Thede, L.Q. (2012) Informatics and nursing: Opportunities and challenges. Online Glossary of terms. http://dlthede.net/Informatics/glossary2.html 